\title{
Czech-Russian Homonymy as a Didactic Problem
}

\section{[Чешско-русская омонимия как лингводидактическая проблема]}

\author{
Elena A. Vasilyeva - Jakub Konecny
}

\section{DOI: 10.18355/XL.2015.08.01.57-67}

\section{Аннотация}

Статья посвящена вопросу чешско-русской омонимии. Данная проблематика рассматривается нами на фоне методики преподавания русского языка в чешской школе. Анализируется понятие межъязыковой омонимии, приводится классификация чешско-русских омонимов. Как подчеркивается в статье, межъязыковая омонимия является трудным явлением, осложняющим процесс обучения русскому языку в чешской школе. С целью помощи учителям русского языка в статью включены также примеры заданий, нацеленных как раз на работу с омонимами. Статья составлена с учётом методики межкультурного образования, внимание уделяется также специфике обучения русскому языку как инославянскому.

Ключевые слова

межъязыковая омонимия, обучение лексике, русский язык, чешский язык

В связи с тем, что чешский и русский язык принадлежат к славянской группе языков, долгое время в рамках общеславянского или праславянского языка они развивались вместе. Лишь с началом формирования древних славянских государств на территориях Юго-Восточной и Восточной Европы из диалектных наречий постепенно формируются самостоятельные славянские языки (древнерусский, древнечешский, древнеболгарский и т.д.). Исторический путь развития, пройденный вместе, наложил отпечаток на структуру славянских языков. В связи с этим мы обнаруживаем значительное сходство между славянскими языками на всех уровнях структуры языка (фонетика, лексика и словообразование, морфология, синтаксис). Однако мы можем наблюдать и расхождения. Это непосредственно касается вопроса омонимии, т.е. процесса звукового и грамматического совпадения семантически не связанных друг с другом языковых единиц (срав. Rozental, 2009: 30). Усиление семантических расхождений, а в дальнейшем возможно и полная антонимичность значения у одинаково звучащих слов стала возможна в результате распада общеславянского языка. Славяне расселяются на все большей территории, утрачиваются столь близкие контакты, отсюда изменяется и лексический состав языка: забываются прежние значения слов или накапливается семантическая дифференциация и возникает семантический разрыв между первоначальными (общеславянским) значениями слова и их новыми значениями. Таким образом возникали межъязыковые омонимы.

В связи с вышесказанным, нам кажется достаточно интересной и оправданной мысль сербского русиста Боголюба Станковича, который считает, что в странах, чьи жители говорят на славянском языке, следует относиться к процессу обучения русскому языку не в русле общепринятого подхода, т.е. обучения русскому языку как иностранному (РКИ), а по-другому. Ученый предлагает путь обучения русскому языку как инославянскому (РКИнсл), т.к. считает, что «процессы мировой глобализации и европейской интеграции приводят (...) к усилению межъязыковых и культурных контактов европейских 
народов, [что] повышает интерес к русскому языку и его роль в международном общении жителей Европы интенсифицируется. В таких условиях провозглашенная Советом Европы политика мультикультурализма и мультилингвизма, подразумевающая владение, как минимум, тремя языками (родным, одним мировым и одним соседним), значительно увеличивает интерес к русскому языку в инославянских странах, между прочим и потому, что развитие межславянского двуязычия, в котором одним является русский, станет солидной основой для будущего развития межславянского многоязычия, так как знание русского языка усиливает рецептивное многоязычие, т.е. понимание и остальных славянских языков (например, говорящему на чешском языке знание русского облегчает понимание польского, или говорящему на болгарском понимание сербского и т.п.) (...) Близкородственность языков не только требует, но даже и диктует своеобразные методологические подходы к изучению русского языка и методические приемы обучения русскому языку в инославянском окружении. Развивая методологию изучения и методику преподавания русского языка как инославянского, а не как иностранного, славянские русисты (...) создадут условия для более быстрого и более экономного обучения русскому языку» (Stankovich, 2009: 15-17).

Межъязыковыми омонимами принято называть слова обоих языков, сходные по степени отождествления по звуковой или графической форме, но имеющие разные значения (Gurevich, 2007). Й. Влчек, однако, обращает внимание на то, что название «чешско-русская омонимия» вызывает некоторые сомнения, т.к. омонимы представляют собой в лексическом плане слова определенного языка, не связанные по происхождению друг с другом, а совпавшие по своему звучанию лишь в процессе развития языка. В отличие от этого, говоря о родственных языках, автор подчеркивает, что очень часто речь идет о словах общего происхождения и значения, отдалившихся друг от друга только в процессе развития отдельных славянских языков. Данные слова, хотя и нередко в синхронном плане обладают противоположным значением, могут в некоторых специфических случаях (например, фразеологизмах) встречаться в обоих языках в тождественном значении ${ }^{1}$ (срав. Vlcek, 1966: 189-190). По настоящему широкое и системное изучение этих явлений началось с 1928 года, с работы М. Кесслера и Ж. Дерконьи на материале французско-английских и англо-французских параллелей. Данными учеными был введен термин «faux amisdutraducteur» («ложные друзья переводчика») - ныне стандартный (Arbuzova, 2012: online).

Существует целый ряд подходов к определению и пониманию омонимии. Для некоторых авторов является важным критерием этимологогенетическая точка зрения, другие авторы считают основной лексикосемантическую точку зрения (срав. Vlcek, 1966: 194). В рамках данной статьи будем придерживаться, вслед за Й. Влчеком, точки зрения А.Н. Гвоздева, который определяет омонимы как слова разного значения и одинакового

1 Например, в единицах «Долг платежсм красен», «красное солнышко», «Красная Поляна» сохранилось в русском слове красный то же значение, как у чешского слова krásný. Некоторые совпадения наблюдаются и в случае слов живот - život. Слово život (в конкретном значении как часть человеческого тела) в чешском языке сохранилось в устаревшем словосочетании «...plod života Tvého...», наоборот, слово живот (как абстрактное существительное, антоним к слову смерть) в русском языке встречается в словосочетаниях «не на живот, а на смерть» или «положить живот на поле брани». (срав. Vlcek, 1966: 190-191) 
звучания, несмотря на часть речи, к которой принадлежат, включая также нарочно совпавшие грамматические формы слов (например: $m p u$ повелительное наклонение глагола тереть и три - количественное числительное в Им. падеже ед. ч.) (срав. Vlcek, 1966: 195).

В плане сопоставления двух или более языков под понятием межъязыковые омонимы понимаются слова с разным значением, которые похожи друг на друга в звуковом и графическом планах (при произношении и на письме встречаются лишь незначительные расхождения). Говоря о межъязыковой омонимии, Й. Влчек считает нужным различать межъязыковые омофоны и межъязыковые омографы (срав. Vlcek, 1966: 203). Различение омофонов и омографов выгодно и с методической точки зрения, т.к. можно рассматривать отдельные случаи независимо друг от друга в рамках работы над определенным видом речевой деятельности.

Действительно, подобное языковое явление представляет трудность не только для переводчиков, но и прежде всего для учителей и методистов.

Прежде чем говорить о работе с омонимией, необходимо сказать несколько слов об обучении лексике на уроках РКИ. В основном в методике РКИ хорошо разработаны вопросы обучения фонетике и грамматике, вопросам обучения лексике уделяется меньшее внимание в силу очевидности самой темы. Каждый урок ориентирован на то, чтобы выучить с учащимися новые слова. Однако в лингводидактике стоит несколько вопросов, связанных с обучением лексике:

1. Дозировка и отбор языкового материала;

2. Принципы и приемы работы на разных языковых уровнях;

3. Эффективность организации работы на уроке, направленной на заучивание и удержание в памяти новых слов.

Трудности в преподавании лексики возникают в связи со сложностью лексической семантики, многоаспектностью слова, обладающего, кроме собственно лексического статуса, еще и грамматическим, словообразовательным, фразеологическим, лингвострановедческим статусами. Кроме того, не стоит забывать об огромном количестве языковых единиц. На начальном этапе при отборе языкового материала необходимо руководствоваться следующими критериями:

1. Частотность употребления слова и общеупотребимость.

2. Соотнесенность с изучаемой темой.

3. Лексическая сочетаемость, т.е. вхождение языковой единицы в речевое клише.

Этот вопрос достаточно хорошо разработан в современной методике. На начальном уровне необходима строгая структурная организация лексики, т.е изучение лексики в тематической группе или фрейме. ${ }^{1}$ (срав. Minskii, 1988; Минский, 1979)

При предъявлении лексики часто учителя допускают ошибки, давая слова в списках. Такое предъявление слов способствует тому, что слова сохраняются лишь в кратковременной памяти, без достаточной тренировки они быстро забываются. Поэтому предъявление лексики должно быть

${ }^{1}$ Понимание фрейма как когнитивной структуры, организующей человеческую деятельность, было впервые разработано Марвином Минским для целей моделирования искусственного интеллекта и Ирвином Гофманом при описании социальных практик. 
мотивировано, желательно, чтобы учащиеся сами искали значение слов по словарям, особенно в текстах, даваемых на дом. Если учитель сразу же предлагает значение слова, то опять же оно долго не удерживается в памяти учащихся.

Работа с толковыми словарями на начальном этапе не целесообразна, т.к. значение нового слова толкуется через ряд следующих незнакомых слов, что может привести лишь к еще большей путанице у учащихся.

Желательно включить новое слово в минимальный контекст. Включение слов в предложение позволяет не только усвоить их значение, но и осознать связи с другими словами, дает образцы употребления новых слов в речи. Однако предложение не должно содержать грамматических трудностей. Учащийся, припоминая контекст, вспоминает и значение нового слова. Запись слова тоже становится хорошей тренировкой, т. к. в сознании взрослого человека образ слова складывается из 3 составляющих: фонетической стороны, семантической и графической.

Кроме того, важно учитывать национально-культурный компонент в семантике слов.

Как было уже сказано выше, чешско-русская омонимия демонстрирует дифференциацию значений слов, доходящую порой до полной антонимичности семантики. Академик Л. В. Щерба писал: «Изучая иностранный язык того или иного народа, мы изучаем исторически сложившуюся у него систему понятий, сквозь которую мы воспринимаем действительность..., а языковые различия связаны отчасти с вполне актуальными различиями в культуре носителей этих языков» (Berdichevskiyi, 2011: 22). Поэтому значение слов, расхождение семантики может быть связано с расхождениями в культуре носителей языков.

В связи с этим выделяется безэквивалентная лексика, та, которая не существует в воспринимающей культуре, например, маршрутка и фоновая лексика - это слова, отличающиеся в родном и изучаемом языках культурными фонами (совокупностью внеязыковых сведений, относящихся к данному слову).

Для чешско-русской омонимии характерны следующие черты (срав. Vlcek, 1966: 206):

1. единицы похожи друг на друга в звуковом плане;

2. единицы похожи друг на друга или полностью сходны в плане графическом;

3. единицы различаются по своему значению;

4. омонимия может касаться как всей парадигмы слов в обоих языках, так и лишь некоторых форм.

Й. Влчек (1966: 205-206) различает следующие группы чешско-русских омонимов:

1. лексическая омонимия: запах - zápach, позор - pozor, дуга - duha, запирать - zapírat, пивовар - pivovar;

2. омонимия в области частей речи: рано (наречие) - ráno (существительное), nодать (существительное) - podat (глагол), мол (междометие) - mol (существительное), шест (существительное) - ̌̌est (числительное), простой (прилагательное) - prostoj (существительное);

3. омонимия в области грамматических форм: постой (повелительное наклонение глагола постоять) - postoj (существительное), шило (существительное) - šilo (прошедшее время глагола шить), высший (в элятивном значении) - vyšš (сравнительная степень прилагательного vysoký); 
4. русско-чешская омофония: княжна - knе̌žna, дело - dělo, отказ odkaz,npyd - prut;

5. русско-чешская омография: родина - rodina, обнова - obnova, потрава - potrava, место - тёsto, мех - тесh, мимо - тіто, точеный-točený.

Чтобы показать возможности работы с данным явлением на уроках русского языка как (второго) иностранного языка в чешской школе, обратимся к некоторым следующим примерам чешско-русской омонимии.

Например, слово svátek (svátky) является омонимом русскому Святки (из *свАтъкъ, см. свято́й. «время от рождества до крещенья», др.-русск. свгатокъ м. (Стихир. XII в.; по Соболевскому, Лекции 212) (срав. Svyatki, 2014: online). Как мы видим, обращение к этимологическому словарю проясняет семантическое сходство слов. Чешское svátky возникло очевидно из праславянского *svent; *свлт. Очевидно, слова имеют общую религиозную основу возникновения -- праздники, связанные с днями почитания божеств. В дальнейшем семантика слова наложилась на христианскую основу и стала обозначать дни поминовения святых ${ }^{1}$. Однако в русской традиции остались Святки языческим праздником с гаданиями и ряжеными. В это время, по преданию, нечистая сила гуляет по земле. С описанием этого праздника связана гоголевская «Ночь под Рождество» или романтическая поэма «Светлана» В. А. Жуковского.

Или слово: крестьянин - zemědělec; křest’an - христианин. В «Этимологическом словаре русского языка» М. Фасмера можем найти следующее значение слова: «Крестьянин (в соврем. знач. - с конца XIV в.), др.русск. крьстыанинъ "христианин; человек"; чеш. křest’an "христианин"». Как видим, в основе семантики обоих омонимов лежит христианское миропонимание. Значит, христианин - человек, живущий простой жизнью, питающийся результатами своего труда.

Например, слово: неделя - týden, neděle - воскресенье. Этимология слова неделя восходит к семантике: «день, в который не делают, не работают», что находит подтверждение и в других славянских языках. В какой-то момент развития языка произошел распад полисемии, что дало интересное значение слова в русском языке.

При работе с омонимией, конечно, возможно обращение к этимологическому словарю и этимологические комментарии для демонстрации сходства и расхождения в семантике слов. Такие комментарии запоминаются студентам и делают заучивание слов осознанным.

Кроме того, работа с омонимией позволяет работать с культурными лакунами, помогая видеть через призму чужой, но близкой культуры свою.

Чешско-русские омонимы по подсчетам Й. Влчека составляют около $10 \%$ словарного запаса обоих языков (Vavrecka, 2007; Vlcek, 1975). Кроме того, большинство из них относится к сфере деятельности человека. Это связано, видимо, с тем, что сфера деятельности человека один из самых древних пластов лексики, относящийся к праславянскому наследию.

Существуют довольно неплохие словари «ложных друзей» переводчиков. К наиболее ранней работе относится словарь Йозефа Влчека «Úskalí ruské slovní zásoby: Slovník rusko-české homonymie a paronymie», представляющий собой наиболее полное собрание всех чешско-русских омонимов (срав. Vlcek, 1966). К более поздним работам относятся работы

${ }^{1}$ Например, такой список в православной традиции называется святцыь. 
Моймира Вавречки (срав. Vavrecka, 2007) и Станислава Жажи (срав. Zaza, 1999).

В методике межкультурной коммуникации выделяется 7 стадий формирования лексического навыка (Е.И. Пассов).

1. Восприятие слова в процессе его функционирования в межкультурной ситуации.

2. Осознание значения слова (семантизация).

3. Имитация использования слова в межкультурной ситуации.

4. Подстановка лексических единиц в микротекст или речевой образец.

5. Воспроизведение (репродукция) - способность называть предмет, объект, действие, качество и т.д.

6. Комбинирование - способность сочетания нового слова с другими словами.

7. Употребление - самостоятельный выбор слова и его сочетание с другими в соответствии с ситуацией.

Первые две стадии - ознакомление со словом; третья, четвертая, пятая тренировка; шестая и седьмая - применение.

Основными приемами семантизации являются: дефиниция (краткое определение понятия с помощью уже известных учащемуся слов), синонимы, антонимы, контекст, зрительная наглядность, словообразовательный анализ.

Последовательность усвоения слов в иностранном языке может быть представлена как слово - предложение - связанная речь. При этом при усвоении слов важны ассоциации, сила эмоционального воздействия слова на учащегося. Чем ярче сила воздействия, тем проще слово запоминается. Потому антонимичное значение некоторых омонимов способствует их прочному усвоению. Например, «vůně - запах; zápach - вонь». «В ассоциациях слово проявляется как понятие, выражающее определенные культурные связи и отношения. Эти связи формируются в памяти благодаря опыту в определенной культуре и оказывают влияние на оценку окружающей действительности». (Berdichevskiyi, 2011: 28)

В качестве примера приведем работу со словами «друг - nриятель - přtel kamarád».

При работе с чешско-русской омонимией необходимо давать толкования слов, а затем тренировать в упражнениях на подстановку. Можно предложить, чтобы учащиеся для себя вели словарь чешско-русских омонимов с их толкованием.

Например, рассмотрим синонимический ряд: знакомый - приятель друг. Чешский př́tel скореe соответствует русскому «друг», так как обозначает более серьезные отношения. Знакомый (человек, которого знаю, но не в близких отношениях) - приятель (человек, с которым приятно провожу время, но не могу доверить свои тайны и открыть душу) - друг (человек, который мне близок, и могу ему доверить все).

Задание. Напишите слова приятель и přtel в центры овалов. Переведите чешское слово на русский язык. Напишите круг ассоциаций, связанный с этими словами в чешской и русской культурах.
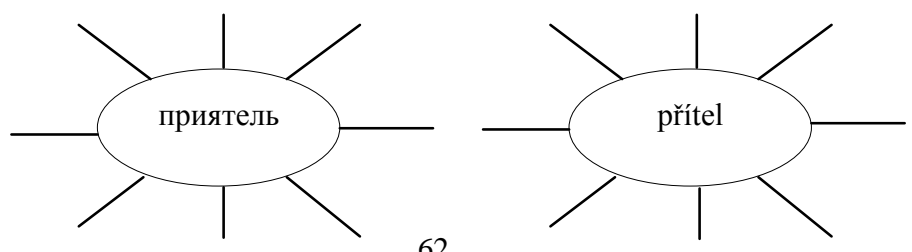
Для правильного выбора слова необходимо учитывать как семантику слов, так и лексическую сочетаемость. Например, друг - верный, лучший, старый; знакомый - вчерашний, случайный. Слово «приятель» в семантическом ряду «друг - приятель» является словом сниженной эмоциональной окраски, поэтому сочетается с разговорной формой глагола беседовать - болтать; болтать с приятелем/приятельницей.

Возможно следующее упражнение. Выпишите к каждому из слов: знакомый друг - приятель подходящие слова. Пользуйтесь словарем.

Слова распределяются в три столбика, под каждым существительным из синонимического ряда.

Затем может следовать упражнение на подстановку.

Задание. Выберите слово знакомый - друг - приятель и вставьте в предложение. Мы всегда вместе с Вадимом, моим лучшим .........., занимаемся рафтингом. Этот вид спорта опасен, и надо прийти на помощь ..........., если случилась беда. C ......... мы болтали в кафе. Мой вчерашний ........... пригласил меня в кино. С.......... мы любим сойтись за чашечкой кофе и поболтать.

Чем больше тренировки в различных упражнениях и играх, тем прочнее усваивается материал. Тренировка лексики - это многократное осознанное выполнение действий в учебных условно - коммуникативных ситуациях, которое обеспечивает не только ее запоминание, но постепенный, управляемый переход в личный опыт учащихся, благодаря чему употребление слова доходит до автоматизма и слова входят в активный словарный запас учащегося. Методисты считают, что дозировка слов на урок должна быть 15-20 слов. Необходимых тренировок, т.е. звучаний слова, должно быть приблизительно 20-25. К тому же необходимо по прошествии времени возвращаться к изученным словам, поддерживая их в активном словарном запасе.

Например, работа над словами zпа́mý - знакомый, известный, знаменитый. Опять же необходимо начать с толкования семантики. Знакомый - только мой; известный - ограничен какой-то территорией или сферой деятельности, знаменитый - знают все.

Задание. Ответьте на вопросы, употребив нужное прилагательное.

1. Учитель из вашей школы. Он ваш знакомый? Известный? Знаменитый?

2. Карел Гот известный? Знакомый? Знаменитый?

3. Писатель Чапек известный? Знакомый? Знаменитый?

4. Подруга моей мамы моя знакомая? Известная? Знаменитая?

Задание. Какое прилагательное надо вставить в предложение? Впишите его, объясняя свой выбор.

Вдруг мы услышали .............. мелодию. Иконопись ............... на Руси с XI века. Экскурсию по музею провел мой............... экскурсовод. Выставку картин открыл ................ художник. Репин написал много портретов ............. русских писателей. Вчера мы встретили художника. Вчера мы встретили одного ............. художника. 
Задание, выводящее на уровень коммуникативной компетенции. Расскажите о знаменитом писателе; известном человеке в вашем городе; вашем знакомом.

Говоря о теме «Искусство», следует также отметить слово umělec, что переводится на русский язык как «деятель искусства»: художник, артист, музыкант. В русском языке умелец - это лишь мастер народного промысла или слово имеет другое значение с негативным оттенком как «ловкий мошенник, вор». Например, "yмельщ̧ы-лохотронщики" - чистейшей воды надувательство (срав. Ответы@Mail.ru: online).

Таким образом, смена стилистической или эмоциональной окраски слова обычно относится к более поздним изменениям в языке.

Например, слово «очи» употребляется в русском языке, но лишь в книжной стихотворной речи.

Часто при изучении определенной темы мы встречаемся с чешскорусской омонимией. При этом можно использовать при введении новых слов наглядность, например, тема «Русская кухня» содержит достаточно много омонимов. Можно предложить учащимся сделать презентацию по списку слов, предложенных учителем, и затем ее представить в классе.

Приведем образцы упражнений по теме «Русская кухня», нацеленные на работу с чешско-русской омонимией.

Задание. Кто быстрее всех впишет в текст отсутствующие слова?

1. Колбаса - это не только klobása, но и

2. Котлета - это не только kotleta, но и

3. Вкус - это не только vkus, но и

4. Масло - это не только máslo, но и

5. Мармелад - это не marmeláda, а

6. Варенье - это не vaření, а

7. Чёрствый - это не čerstvý, a

8. Закуска - это не zákusek, a

9. Печень - это не рес̌еnе̌, a

10. Капуста - это не kapusta, a ...

11. Сметана - это не smetana, a

12. Калач - это не koláč, a

С темой «Питание» также связан глагол dát - dávat něco někam. Рассмотрим эквиваленты чешского выражения dát-dávat něco někam в русском языке.

Dát - dávat něco někam / někomu - 1. Положить - класть что-нибудь куда-нибудь. 2. Поставить - ставить что-нибудь куда-нибудь. 3. Дать - давать кому-нибудь что-нибудь.

Например, Dej na stůl talíre a sklenice. - Поставь на стол тарелки и стаканы. Dej na stůl ubrus, př́bory a ubrousky. - Положи на стол скатерть, приборы и салфетки.

Задание. Переведите на русский язык.

Kolik tam mám dát cibule?.

Dej tam malou lžičku koření!

Dala jsi na stůl talířky?

Kolik cukru dáváš do čaje?

Nedávej tu váhu na stůl!

Proč jsi nedal na stůl sklenice na pivo?

Nezapomeň dát do polévky petržel!.

A nemám tam dát i mrkev?.. 
Задание. Ещё раз посмотрите предыдущее задание. Закройте левый столбец, переведите то, что вы записали в правом столбце, на чешский язык.

Наиболее часто на практике встречаются ошибки в употреблении следующих омонимов: rád - pad, pozdravit - поздравить, dostat - достать, zapomenout запомнить и т.д. Остановимся лишь на некоторых из них и приведем примеры работы.

Rád-pad. Чешское rád в переводе на русский язык. Учителю следует обратить особое внимание учащихся на факт, что русское «рад» никогда не сочетается с личной формой глагола.

1. Mám rád - я люблю.

Jsem rád, že vás vidím - a) рад + инфинитив (только в клише): Я рад вас видеть.

Jsem rád, že jste přijel - б) рад, что..... Я рад, что вы приехали.

Jsem rád, že jste přijel - в) рад + дательный падеж: Мы рады вашему приезду.

2. Rád něco dělám - я люблю танцевать, читать.....

3. Rád něco udělám - я с удовольствием(с радостью) вам помогу.

Задание. Переведите на русский язык.

Rád vás doprovodím. Jsem ráda, že se ti to podařilo. Můj bratr velmi rád tančí. Jsme rádi, že už jste tady. Neprodala byste mi ty noviny? Ráda. Jsem rád, že vás zase vidím. Otec má rád fotbal, bratr zase hokej. Co máš raději - brambory nebo knedlíky? Rád čteš? Rádi vám pomůžeme. Jsme rádi, že to tak dopadlo. Ty nerada tančíšs?

В конце хотелось бы привести небольшой список омонимов, на наш взгляд, достаточно интересных, которые проясняют семантику других слов, образованных в результате распада полисемии.

Lstivý - коварный; льстивый - podlézavý (разг. podlízavý). Данная омонимия также объясняет семантику русского слова «подлиза» - Человек, который подлизывается, льстит. (Tolkovyiy slovar Ozhegova). Однако слово «лестный pochvalný» имеет положительную окраску.

Soutěžit - сутяжить. В «Толковом словаре» В. И. Даля находим: «СУТЯЖИТЬ, сутяжничать, заводить тяжбы, споры по суду, тягаться, судиться вздорно, придирчиво, стараясь оттягать что-нибудь. Сутяженье или сутяжничанье, действие по глаг. Сутяжество, -жничество, то же, но более как свойство или дело...» (Sutyazhit: online). Чешско-русская омонимия помогает понять семантику данного слова. Значит, общение с судами нечто вроде соревнований (soutěžit - соревноваться).

Malovat - рисовать; малевать (сниж. разг.) - čmárat.

Těšit se - ждать с нетерпением; тешиться (однокор. утеха, утешение) (ср. чем бы дитя не тешилось, лишь бы не плакало - фразеологизм). М. Фасмер считает, что слово происходит от корня -тих- (х/ш - общеславянские чередования) (срав. Teshit, 2014: online), однако материалы других славянских языков подтверждают, что слово с подобным корнем имело и другое значение в славянских языках, как «готовить, устраивать», «баловать» и т.д. Однако общим является семантика доброго чувства, спокойного и радостного.

О необходимости уделять данной проблематике внимание не только с теоретической точки зрения, но и с точки зрения методической и переводческой писал Й. Влчек в заключении своей работы уже в 1966 г. (срав. 
Vlcek: 1966, 228). Однако, необходимо подчеркнуть, что его словарь остается до сих пор единственной обобщающей и комплексной работой, на которую можно опереться, говоря о чешско-русской омонимии.

Языки - живое явление, и с течением времени они претерпевают различные изменения, в том числе касающиеся и их лексического состава. На наш взгляд, перспектива исследования данной темы состоит в том, чтобы проследить новые тенденции развития чешско-русской омонимии, связанные с обновлением словарного запаса языков.

\section{References}

ARBUZOVA, N.V. 2012. Mezhyazykovaya omonimiya v rechi anglo-nemetskikh bilingvov v Shveytsarii. In: Teoretyczne i practyczne innowacje w nauce [online]. Gdansk. [cit. 2014-04-05]. URL: <http://konferentsiya.com.ua/pages/view/605> (slovo konferentsiya nuzhno pisat azbukoy, inache veb-sayt ne otkoyetsya).

BERDICHEVSKIYI, A.L. et al. 2011. Metodika mezhkulturnogo obrazovaniya sredstvami russkogo jazyka kak inostrannogo. Moskva: Russkij jazyk. Kursy. ISBN 978-5-88337-253-6

GOFMAN, I. 2000. Predstavleniye sebya drugimi v povsednevnoy zhizni. Perevod s angliyskogo A. D. Kovaleva. Institut sociologii RAN [i dr.]. Moskva: Kanon-PressC. ISBN 5-93354-006-4

GUREVICH, T. 2007. Mezhyazykovaya omonimiya, paronimiya (na primere angliyskogo yazyka). „Lozhnyye druzya“ perevodchika. Znaniye. Ponimaniye. Umeniye. [online]. E-mail publikatsii. [cit. 2014-04-05]. URL: <http://www.zpujournal.ru/zpu/e-publications/2007/Gurevich_T/>.

MINSKII, M. 1979. Freymy dlya predstavleniya znaniy. Moskva: Mir.

MINSKII, M. 1988. Ostroumiye I logika kognitivnogo bessoznatelnogo. In: Novoye v zarubezhnoy lingvistike, n.23

OTVETY@Mail.ru: V chem negativnoye znacheniye BADov? In: Mail.RU [online]. Neuvedeno [cit. 2014-04-20]. URL: <http://otvet.mail.ru/question/84013146>.

ROZENTAL, D.E. - GOLUB, I.B. - TELENKOVA, M.A.. 2009. Sovremennyy russkiy yazyk. 11 izd. Moskva: Ayris-Press. ISBN 978-5-8112-3636-7

STANKOVICH, B. 2009. O perspektivakh rusistiki v slavyanskom mire. In: Russkiy yazyk kak inoslavyanskiy: sovremennoye izucheniye russkogo yazyka i russkoy kultury v inoslavyanskom okruzheniyi. Belgrad: Chigoya shtampa, 14-21pp. ISSN 1821-3146

SUTYAZHIT. In. Tolkovyy slovar Dalya: Yandeks.Slovari [online]. (C) 2001-2014 [cit. 2014-04-20]. URL: <https://slovari.yandex.ru>.

SVYATKI: Etimologicheskiy slovar russkogo yazyka. Fasmer Maks (onlayn versiya). 2014. Classes.ru: Angliyskiy yazyk dlya vsekh [online]. [cit. 2014-04-05]. URL: <http://www.classes.ru/all-russian/russian-dictionary-Vasmer-term-11761.htm>.

TESHIT: Etimologicheskiy slovar russkogo yazyka. Fasmer Maks (onlayn online versiya). 2014. Classes.ru: Angliyskiy yazyk dlya vsekh [online]. [cit. 2014-04-05]. URL: <http://www.classes.ru/all-russian/russian-dictionary-Vasmer-term-13515.htm>. VAVRECKA, M. 2007. Ruska slovesa a jejich ceske ekvivalenty. Brno: Computer Press. ISBN 978-80-251-1471-1

VLCEK, J. 1966. Uskali ruske slovni zasoby: Slovnik rusko-ceske homonymie a paronymie. Praha: Svet sovetu, 1966.

VLCHEK, I. 1975. Cheshsko-russkiye omonimy - vysshaya stadiya leksicheskoy interferentsiyi. In: Bolgarskaya rusistika, pp. 33-52.

ZAZA, S. 1999. Rustina a cestina v porovnávacím pohledu. Brno: Masarykova univerzita. ISBN 80-210-2058-X 
Words: 3810

Characters: 29940 (16,63 standard pages)

Mgr. Elena A. Vasilyeva, CSc.

Department of Slavonic Studies

Faculty of Education

University of Hradec Kralove

Rokytanskeho 62

50003 Hradec Kralove

Czech Republic

elena.vasilyeva@uhk.cz

Mgr. Jakub Konecny

Russian \& Language Teaching Methodology Department

Faculty of Education

Charles University in Prague

Magdaleny Rettigove 4

11639 Prague

Czech Republic

jakub.konecny@pedf.cuni.cz. 